\title{
Endovascular solution in a complex post-dissectional thoracic aortic aneurysm case
}

\author{
Kompleks bir diseksiyon sonrası torasik aort anevrizma olgusunda endovasküler çözüm
}

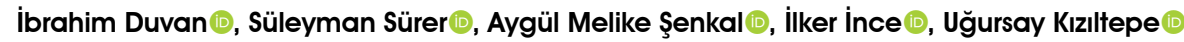 \\ Department of Cardiovascular Surgery, Health Sciences University, Dışkapı Yıldııım Beyazıt Training and Research Hospital, Ankara, Turkey
}

\begin{abstract}
A 45-year-old male patient presented to our clinic with a post-dissectional thoracic aortic aneurysm with the retrograde filling of the false lumen. He previously underwent a Bentall operation and a proximal thoracic endovascular aortic repair. We carried out a bare metal stent implantation concomitant with endograft extension and stent-assisted balloon-induced intimal disruption and relamination procedure consecutively. Although true lumen expansion was achieved, the aneurysmatic dilation of the descending thoracic aorta was kept on expanding due to perfusion of the false lumen by the distal re-entries. Therefore, it was decided to perform a totally false lumen thrombosis by the candy-plug technique. In conclusion, despite being a fatal disease, endovascular treatment of post-dissectional thoracic aortic aneurysm post-dissectional thoracic aortic aneurysm is possible in anatomically suitable patients with a stepwise approach in experienced endovascular centers.
\end{abstract}

Keywords: Dissecting aneurysm, embolization, endovascular procedures, stent, thoracic aorta.

Aortic dissection (AD) has a tendency to dilate and progress to an aneurysm. Surgical or interventional aortic repair is recommended, when the diameter of the descending aorta is $>5.5 \mathrm{~cm}$ and/or rapidly growing $(0.5 \mathrm{~cm} / 6$ months $)$ in chronic dissections. ${ }^{[1]}$

Thoracic endovascular aortic repair (TEVAR) has gained a trustworthy and impressive popularity in the treatment of acute-chronic and/or complicateduncomplicated Type III ADs. The main goal of TEVAR is to achieve a uniluminal flow in the
$\ddot{O} Z$

Diseksiyon sonrasında yalancı lümeninin retrograd doluşu ile torasik aort anevrizması olan 45 yaşında bir erkek hasta kliniğimize başvurdu. Hasta daha önce Benthal ameliyatı ve proksimal torasik endovasküler aort onarımı geçirmişti. Hastaya sırasıyla, çıplak metal stent implantasyonu ile birlikte endogreft uzatma ve stentle desteklenen, balon indüksiyonu ile intimada yırtık oluşturulan alanda reappozisyon uygulandı. Gerçek lümenin genişlemesinin sağlanmasına rağmen, distal re-entryler aracılığıyla yalancı lümen perfüzyonunun devam etmesi nedeniyle, inen torasik aortun anevrizmatik dilatasyonunun ilerlediği görüldü. $\mathrm{Bu}$ nedenle, candy-plug tekniği ile yalancı lümenin tamamen tromboze olmasının sağlanmasına karar verildi. Sonuç olarak, ölümcül bir hastalık olmasına rağmen, diseksiyon sonrası torasik aort anevrizmanın anatomik olarak uygun olan hastalarda, deneyimli merkezlerde, aşamalı yaklaşımlarla endovasküler yöntemler uygulanarak tedavisi mümkündür.

Anahtar sözcükler: Dissekan anevrizma, embolizasyon, endovasküler işlemler, stent, torasik aort.

thoraco-abdominal aortic course by abolishing the proximal tear, leading the flow to the true lumen (TL) and inducing thrombotic obliteration of the false lumen (FL) and performing a complete aortic remodeling. ${ }^{[2]}$

False lumen thrombosis should be the main target of the treatment modalities in chronic Type III ADs, since patency of the FL prohibits positive aortic remodeling and decreases survival. ${ }^{[3]}$ Unfortunately, TEVAR alone is not sufficiently capable to remodel

Received: January 31, 2021 Accepted: May 11, 2021 Published online: October 20, 2021

Correspondence: İbrahim Duvan, MD. SBÜ Dışkapı Yıldırım Beyazıt Eğitim ve Araştırma Hastanesi Kalp ve Damar Cerrahisi Kliniği, 06110 Dışkapı, Ankara, Türkiye. Tel: +90 312 - 4572383 e-mail: ibrahimduvan@hotmail.com 
the dissected aorta. Neither the perfusion of FL via the distal re-entries located at visceral level, nor the endoleaks can be eliminated by TEVAR alone.

Furthermore, serious complications such as stentinduced distal re-dissection (SIDR) may occur due to size discrepancy between the proximal undissected landing zone and distal, collapsed and, most of the time, narrowed TL.

Herein, we present a case of bare metal stent (BMS) implantation in the shrunk visceral level and the use of proximal part of BMS as a distal landing zone for concomitant TEVAR extension ${ }^{[4]}$ along with stent-assisted balloon-induced intimal disruption and relamination (STABILISE) ${ }^{[5]}$ and candy-plug ${ }^{[6]}$ procedures to achieve elimination of $\mathrm{FL}$ and aortic remodeling.

\section{CASE REPORT}

A 45-year-old male patient presented to our department with a complaint of a back pain and dyspnea, suggesting a post-dissectional thoracic aortic aneurysm (PDTAA) as evidenced by computed tomography angiography (CTA). He previously underwent a Bentall operation and TEVAR at an external center. The CTA demonstrated a 120-mm PDTAA with retrograde filling from the distal FL due to a re-entry located superior to the celiac trunk. The TL was severely shrunk due to compression of the perfused FL by the distal re-entries, but the visceral arteries originated from the TL (Figure 1a). We planned to support the
TL in the distal descending thoracic and visceral arterial perfusion of the abdominal aorta via a BMS implantation and TEVAR extension to eliminate distal re-entry. A written informed consent was obtained from the patient.

\section{Bare metal stent implantation and TEVAR extension (provisional extension to induce complete attachment [PETTICOAT])}

Under local anesthesia with sedoanalgesia, the right femoral artery was cannulated surgically, whereas the left femoral artery was cannulated percutaneously. After having visualized the entire aorta and confirmation of the TL (Figure 1b), a $36 \times 32 \times 130-\mathrm{mm}$ E-XL BMS (Jotec $\mathrm{GmbH}$, Hechingen, Germany) was deployed between the supraceliac and the infrarenal region (Figure 1c). Subsequently, TEVAR extension was carried out by a $42 \times 42 \times 200-$ mm Valiant $^{\mathrm{TM}}$ (Medtronic, Minneapolis, MN, USA) thoracic stent graft between the previously deployed TEVAR endograft and the E-XL BMS just proximal to the celiac trunk (Figure 1d). The use of proximal extension of a BMS as a distal landing zone for TEVAR extension was preferred to prevent fatal complications caused by distal size mismatch such as SIDR, type 1B endoleak and TL rupture. ${ }^{[4]}$

Control CTA revealed TL expansion, but FL perfusion and retrograde filling of the aneurysm still persisted and dissection was expanding to the left common iliac artery (Figure 1e). Therefore, the STABILISE Procedure was decided as the next step.
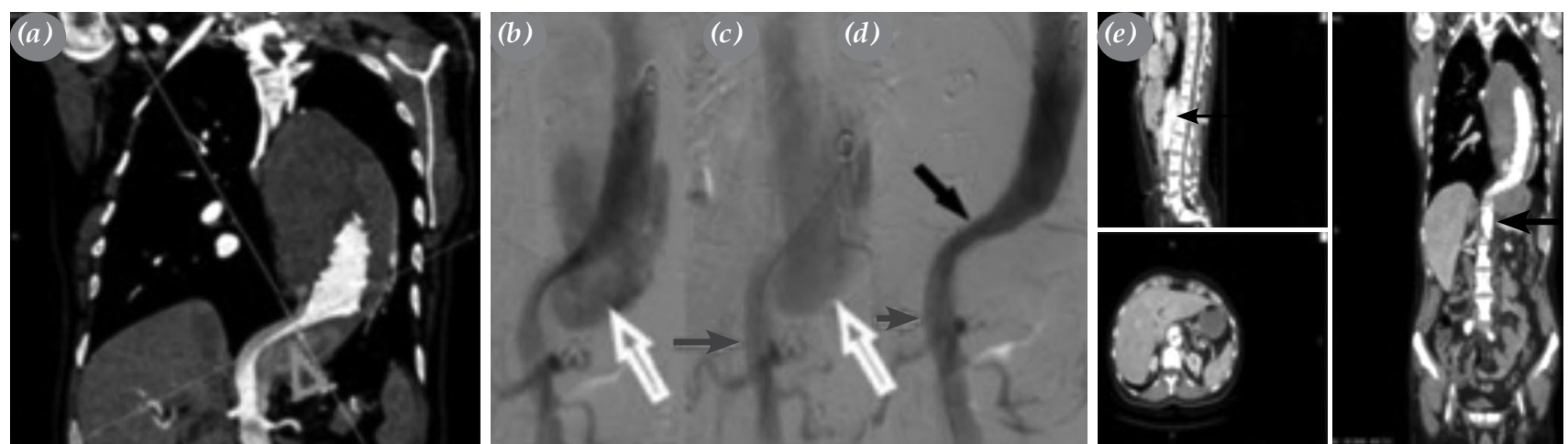

Figure 1. Preoperative coronal CTA view of the PDTAA, perioperative angiographic views during the modified PETTICOAT procedure and sagittal, axial and coronal CTA views after the modified PETTICOAT procedure. (a) Tortuosity at the diaphragmatic region of the aorta and shrinkage of the true lumen (triangle). (b) Angiographic view of the FL perfusion by distal re-entries (white arrow). (c) Angiographic view of the FL (white arrow) and BMS in the visceral region of the abdominal aorta (gray arrow). (d) Completed view of the modified PETTICOAT Procedure. BMS (gray arrow) and TEVAR extension endograft deployed in BMS (black arrow). (e) CTA view of the perfused FL in multiplanar reconstruction after modified PETTICOAT procedure (black arrow).

CTA: Computed tomography angiography; PDTAA: Post-dissectional thoracic aortic aneurysm; FL: False lumen; BMS: Bare metal stent; TEVAR: Thoracic endovascular aortic repair; PETTICOAT: Provisional extension to induce complete attachment. 

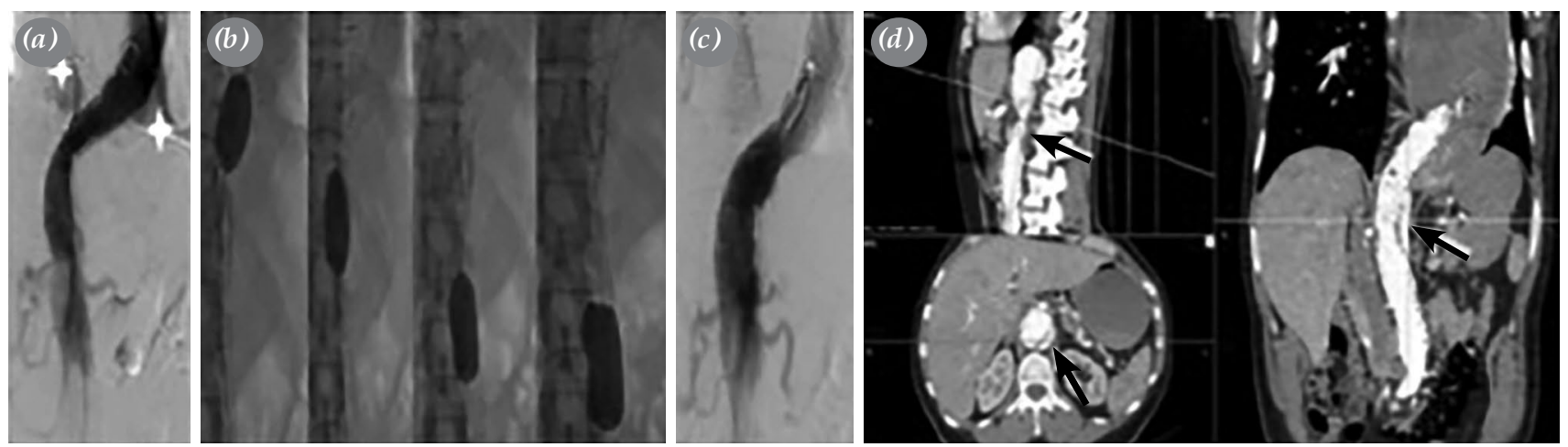

Figure 2. Intraoperative angiographic views of STABILISE procedure: sagittal, axial and coronal CTA views of PDTAA after STABILISE. (a) Perfusion of the FL demonstrated in the distal descending thoracic aorta before the STABILISE procedure (white stars). (b) Manual inflation of the reliant balloon from distal one third of the $2^{\text {nd }}$ TEVAR to BMS craniocaudally. (c) Completion of the STABILISE procedure. (d) Perfusion of the FL demonstrated by CTA in multiplanar reconstruction (black arrows).

STABILISE: Stent-assisted balloon-induced intimal disruption and relamination; CTA: Computed tomography angiography; PDTAA: Post-dissectional thoracic aortic aneurysm; FL: False lumen; BMS: Bare metal stent; TEVAR: Thoracic endovascular aortic repair.

\section{STABILISE procedure}

Under local anesthesia with sedoanalgesia, the right femoral artery was cannulated percutaneously and prepared for the Perclose ProGlide ${ }^{\circledR}$ (Abbott Vascular, Santa Clara, CA, USA) vascular closure system. Following aortography (Figure 2a), a 46-mm
Reliant $^{\mathrm{TM}}$ Stent Graft Balloon Catheter (Medtronic Inc., Minneapolis, MN, USA) was manually inflated under fluoroscopic guidance from the distal one-third of the second TEVAR stent graft down to the distal end of BMS (Figure 2b). Multiple inflations were carried out to achieve reapposition of the disrupted
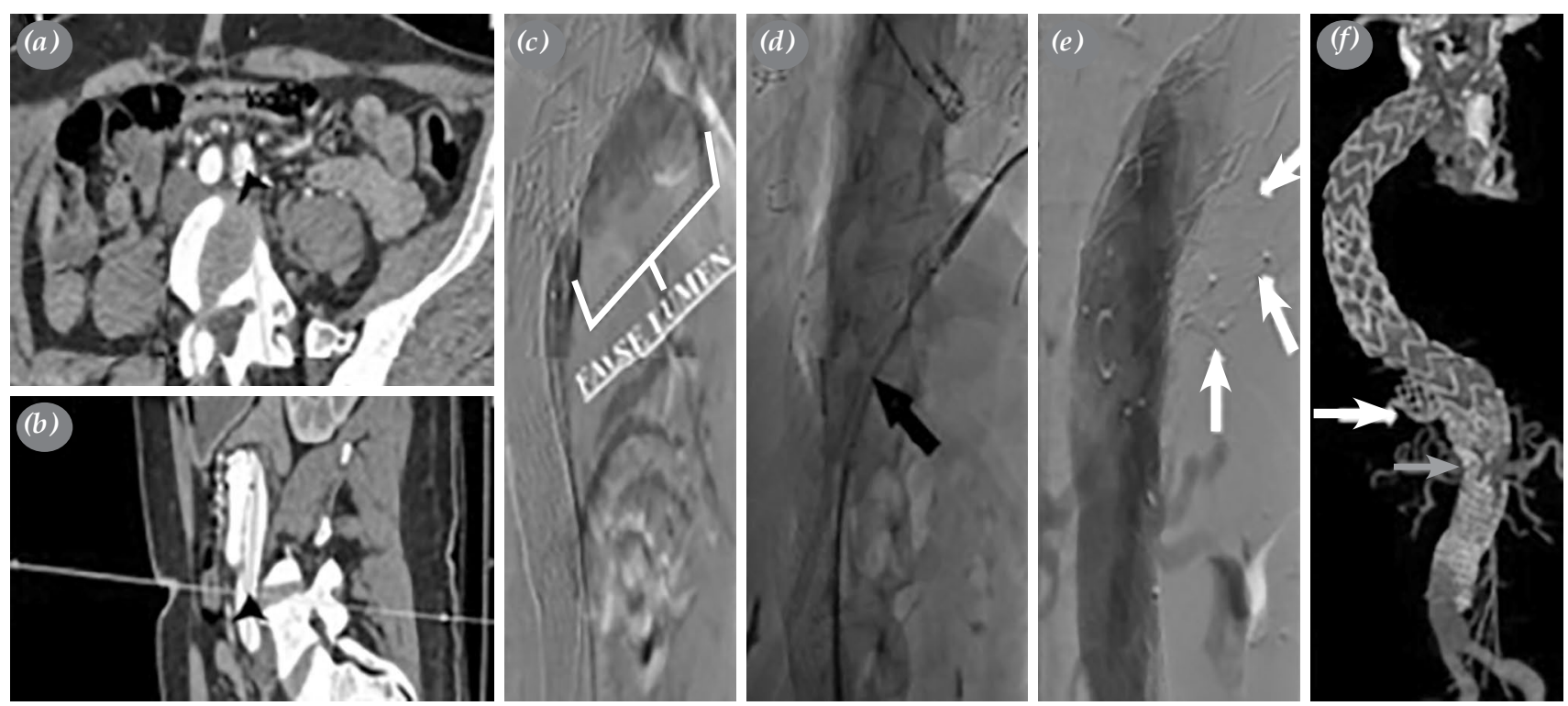

Figure 3. Planning of the candy-plug technique by CTA views, intraoperative angiographic views of performing the candy-plug technique and the postoperative three-dimensional CTA view of the candy-shaped and vascular plug. (a, b) Access region to the false lumen next to the $2^{\text {nd }}$ TEVAR endograft via the major re-entry in the left common iliac artery demonstrated by CTA in multiplanar reconstruction axial and sagittal views (black arrowhead). (c) Angiographic demonstration of the false lumen next to the $2^{\text {nd }}$ TEVAR endograft (white bracket). (d) Insertion of the re-sheathed ETEW graft into the false lumen side by side with the $2^{\text {nd }}$ TEVAR endograft (black arrow). (e) Deployment of the surgeon-modified candy-shaped plug side by side with the $2^{\text {nd }}$ TEVAR endograft (white arrows). (f) Three-dimensional view of the candy-shaped plug (white arrow), vascular plug (gray arrow), and total aortic remodeling.

CTA: Computed tomography angiography; TEVAR: Thoracic endovascular aortic repair. 
Table 1. Diametric findings of the aneurysmatic descending thoracic aorta and the true and false lumen in selected regions of the abdominal aorta

\begin{tabular}{lcccc}
\hline & $\begin{array}{c}\text { Operated } \\
\text { Bentall and TEVAR }\end{array}$ & $\begin{array}{c}\text { Post-modified } \\
\text { PETTICOAT }\end{array}$ & Post-STABILISE & Post-candy plug \\
\hline Descending thoracic aorta & $120 \mathrm{~mm}$ & $115 \mathrm{~mm}$ & $114 \mathrm{~mm}$ & $110 \mathrm{~mm}$ \\
Supra-celiac & FL: $2.02 \mathrm{~cm}$ & FL: $1.27 \mathrm{~cm}$ & FL: $0.92 \mathrm{~cm}$ & FL: Thrombosed \\
& TL: $1.27 \mathrm{~cm}$ & TL: $2.24 \mathrm{~cm}$ & TL: $3.65 \mathrm{~cm}$ & TL: Total \\
Superior mesenteric artery & FL: $1.80 \mathrm{~cm}$ & FL: $1.08 \mathrm{~cm}$ & FL: $1.04 \mathrm{~cm}$ & FL: Thrombosed \\
& TL: $1.09 \mathrm{~cm}$ & TL: $2.11 \mathrm{~cm}$ & TL: $2.75 \mathrm{~cm}$ & TL: $2.62 \mathrm{~cm}$ \\
Infrarenal aorta & FL: $1.75 \mathrm{~cm}$ & FL: Thrombosed & FL: Thrombosed & FL: Thrombosed \\
& TL: $0.85 \mathrm{~cm}$ & TL: Total & TL: Total & TL: Total \\
Terminal abdominal aorta & FL: $1.93 \mathrm{~cm}$ & FL: $1.90 \mathrm{~cm}$ & FL: $1.85 \mathrm{~cm}$ & FL: $1.80 \mathrm{~cm}$
\end{tabular}

TEVAR: Thoracic endovascular aortic repair; PETTICOAT: Provisional extension to induce complete attachment; STABILISE: Stent-assisted balloon-induced intimal disruption and relamination; FL: False lumen; TL: True lumen.

intima to the outer aortic wall, elimination of the FL, thus retrograde filling of the proximal aneurysm, constitution of a uniluminal flow and, finally, aortic remodeling (Figure 2c).

Control CTA at four postoperative months revealed a collapsed, but still patent FL and persistent retrograde filling of the aneurysm (Figure 2d). Therefore, we decided to obliterate the FL perfusion totally and accomplish total aortic remodeling by the candy-plug technique in this challenging patient.

\section{The candy-plug technique}

An ETEW Iliac Extension $28 \times 28 \times 82 \mathrm{~mm}$ graft (Medtronic Inc., Minneapolis, MN, USA) was deployed back table and a candy-shaped plug was made by placing two circumferential sutures in the middle of the endograft to obtain a narrowed central lumen for
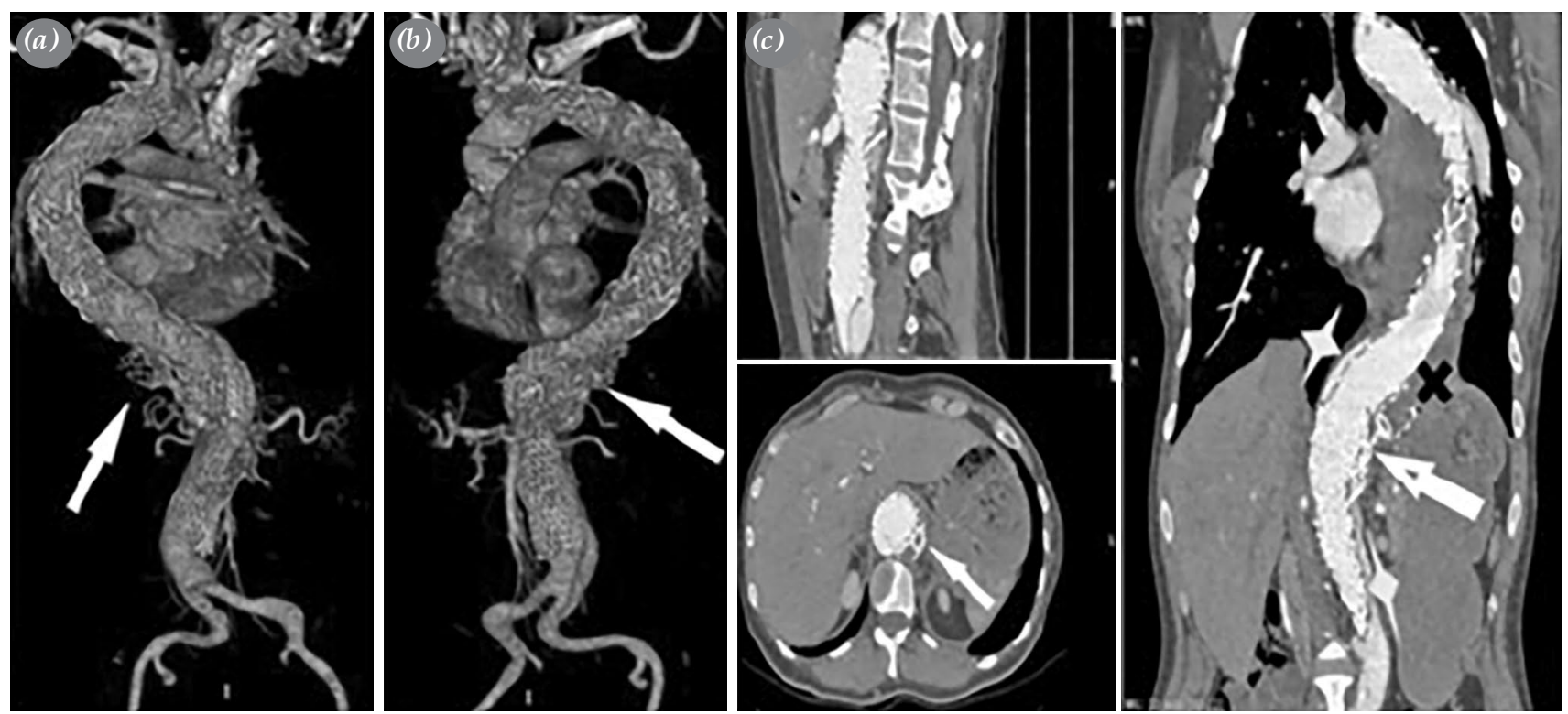

Figure 4. Postoperative the $5^{\text {th }}$ month $3 \mathrm{D}$ CTA with sagittal, axial, and coronal views of the case. (a) 3D posterior CTA view of thoracoabdominal aorta, candy plug, and vascular plug (white arrow). (b) 3D anterolateral CTA view of thoracoabdominal aorta, candy plug, and vascular plug (white arrow). (c) Perfusion of the FL via distal re-entries demonstrated by CTA in multiplanar reconstruction (white star), candy plug and vascular plug (white arrow), thrombosed FL of the descending thoracic aorta proximal to the candy-shaped plug (black cross).

3D: Three-dimensional; CTA: Computed tomography angiography; FL: False lumen. 
post-deployment removal of delivery system, which would be obliterated with an additional vascular plug after deployment and, then, the candy-shaped ETEW endograft was re-sheathed carefully.

After cannulation of the FL via a re-entry in the left common iliac artery and visualization of both lumens, the re-sheathed endograft (candy plug) was advanced proximally in the FL next to the distal end of the second TEVAR graft and deployed side by side to the graft. After removal of the delivery system, the residual lumen was obliterated with a 22-mm Amplatzer $^{\mathrm{TM}}$ Vascular Plug II (AVP; St. Jude Medical, St. Paul, MN, USA) successfully (Figure 3a-f).

The CTA which was performed at 10 weeks revealed the disappearance of the retrograde filling of the aneurysm and total thrombosis of the FL at the supraceliac aorta with a very narrow, thrombosed FL at visceral level without dilation of the aorta (Table 1).

Five months later, his dyspnea resolved, and CTA showed the shrinkage of the thoracic aneurysm (Figure 4a,-c).

\section{DISCUSSION}

Depending on its type, AD is a life-threatening disease due to fatal complications such as malperfusion, aneurysmal dilation, and rupture. In our case, symptomatic and progressive aneurysmal dilation due to retrograde filling from the distal FL via distal re-entries was the indication for the intervention.

Bertoglio et al. ${ }^{[4]}$ reviewed the PETTICOAT concept in the treatment of Type III AD. In 11 studies, 439 patients were examined, of whom 90 were chronic AD patients. They concluded that the PETTICOAT procedure should be performed as a bailout ancillary intervention for TEVAR, only in patients suffering from dynamic malperfusion. In our patient, despite the absence of malperfusion, we chose to perform the modified PETTICOAT procedure to protect the distal end of the TEVAR graft from overexpansion to avoid serious complications, such as SIDR, due to size mismatch of the distal end of the TEVAR extension procedure.

Furthermore, the STABILISE technique was performed at the chronic stage (420 days after deployment of the first TEVAR endograft) in our case to attempt to obliterate the FL and stop the retrograde filling of the aneurysm, despite some evidence showing higher success at acute phase due to a less stiff nature of the dissection membrane. ${ }^{[7,8]}$ Faure et al. ${ }^{[5]}$ performed the STABILISE procedure in 17 chronic (3 to 67 months) complicated Type III
AD patients with diameters of $>55 \mathrm{~mm}$ or rapidly growing in PDTAA. The abdominal FL patency of only two patients persisted due to incomplete intimal disruption and they were not the most chronic cases (224 and 271 days). One of the reasons for failure of disrupting the stiffer septum was considered the insufficient BMS radial force, particularly in the tortuous region of the aorta at the diaphragmatic level. ${ }^{[4]}$ Our patient's aortic anatomy was similar (Figure 1a-d and 2a) with the definition of those two patients in whom complete aortic remodeling could not be achieved. Due to perseverance of retrograde perfusion of the FL via the distal reentries after the aforementioned interventions, it was aimed to promote FL thrombosis by direct embolization at the level of the distal descending aorta through the candy-plug technique.

Rohlffs et al. ${ }^{[6]}$ chose the candy-plug technique to occlude the FL in 18 PDTAA patients. The technical success rate was $100 \%$, whereas the clinical success rate was $94 \%$. In the follow-up period, 15 patients accomplished total FL embolization. They defined the candy-plug technique as a promising technique to achieve complete FL occlusion in complicated chronic AD patients, not only due to being a less invasive technique, but also owing to these successful results. The candy-plug technique was also the most proper FL embolization procedure in our case, as it was a simpler and less invasive technique compared to open repair ${ }^{[8]}$ or fenestrated/branched endovascular grafts..$^{[9,10]}$ In our case, complete FL occlusion was accomplished from the descending thoracic aorta to the distal region of the renal arteries as expected, by utilizing the candyplug technique, and the FL was stable in the terminal abdominal aorta (Table 1).

In conclusion, despite being a fatal disease, endovascular treatment of post-dissectional thoracic aortic aneurysm is possible in anatomically suitable patients with a stepwise approach in experienced endovascular centers.

\section{Declaration of conflicting interests}

Prof. Dr. Uğursay Kızıltepe is 'proctor' in MEDTRONIC but none of us (all of the authors) have no conflicts of interest with respect to the authorship and/or publication of this article.

\section{Funding}

The authors received no financial support for the research and/or authorship of this article.

\section{REFERENCES}

1. Hiratzka LF, Bakris GL, Beckman JA, Bersin RM, Carr VF, Casey DE Jr, et al. 2010 ACCF/AHA/AATS/ACR/ 
ASA/SCA/SCAI/SIR/STS/SVM guidelines for the diagnosis and management of patients with Thoracic Aortic Disease: A report of the American College of Cardiology Foundation/American Heart Association Task Force on Practice Guidelines, American Association for Thoracic Surgery, American College of Radiology, American Stroke Association, Society of Cardiovascular Anesthesiologists, Society for Cardiovascular Angiography and Interventions, Society of Interventional Radiology, Society of Thoracic Surgeons, and Society for Vascular Medicine. Circulation 2010;121:e266-369.

2. Riambau V, Böckler D, Brunkwall J, Cao P, Chiesa R, Coppi $\mathrm{G}$, et al. Editor's choice - management of descending thoracic aorta diseases: Clinical practice guidelines of the European Society for Vascular Surgery (ESVS). Eur J Vasc Endovasc Surg 2017;53:4-52.

3. Akutsu K, Nejima J, Kiuchi K, Sasaki K, Ochi M, Tanaka $\mathrm{K}$, et al. Effects of the patent false lumen on the long-term outcome of type B acute aortic dissection. Eur J Cardiothorac Surg 2004;26:359-66.

4. Bertoglio L, Rinaldi E, Melissano G, Chiesa R. The PETTICOAT concept for endovascular treatment of type B aortic dissection. J Cardiovasc Surg (Torino) 2019;60:91-9.

5. Faure EM, El Batti S, Sutter W, Bel A, Julia P, Achouh $\mathrm{P}$, et al. Stent-assisted balloon dilatation of chronic aortic dissection. J Thorac Cardiovasc Surg 2020:S00225223(20)30430-X.

6. Rohlffs F, Tsilimparis N, Fiorucci B, Heidemann F, Debus ES, Kölbel T. The Candy-plug technique: Technical aspects and early results of a new endovascular method for false lumen occlusion in chronic aortic dissection. $\mathbf{J}$ Endovasc Ther 2017;24:549-55.

7. Faure EM, El Batti S, Abou Rjeili M, Julia P, Alsac JM. Mid-term outcomes of stent assisted balloon induced intimal disruption and relamination in aortic dissection repair (STABILISE) in acute type B aortic dissection. Eur J Vasc Endovasc Surg 2018;56:209-15.

8. Duvan I, Surer S, Ince I, Seren M, Ersoy O, Altinay L, Senkal M, Dolgun A, Karapınar K, Kiziltepe U. Stent-assisted balloon-induced intimal disruption and relamination procedure to achieve aortic remodelling in DeBakey type III aortic dissections. Turk Gogus Kalp Dama 2020;28(Suppl 1):143.

9. Jones DW, Goodney PP, Nolan BW, Brooke BS, Fillinger MF, Powell RJ, et al. National trends in utilization, mortality, and survival after repair of type B aortic dissection in the Medicare population. J Vasc Surg 2014;60:11-9.

10. Oikonomou K, Kopp R, Katsargyris A, Pfister K, Verhoeven EL, Kasprzak P. Outcomes of fenestrated/branched endografting in post-dissection thoracoabdominal aortic aneurysms. Eur J Vasc Endovasc Surg 2014;48:641-8 